Emerson A. Moffitt MD, Dhun H. Sethna MD, John A. Bussell MD, Marjorie J. Raymond RN, Jack M. Matloff MD, Richard J. Gray MD

\title{
Effects of intubation on coronary blood flow and myocardial oxygenation
}

Effects on haemodynamics and myocardial oxygenation of endotracheal intubation were examined in 17 patients after halothane induction and 12 after $1 \mathrm{mg} \cdot \mathrm{kg}^{-1}$ of $\mathrm{IV}$ morphine. Six patients having each anaesthetic were pretreated with $I V$ propranolol $\left(0.1 \mathrm{mg} \cdot \mathrm{kg}^{-1}\right) 45$ minutes earlier. Arterial and intracardiac pressures, cardiac output and total coronary sinus blood flow (CSBF), both by thermodilution, were determined plus arterial-coronary differences of oxygen, haemoglobin and lactate. Blood pressure $(B P)$, heart rate and $C S B F$ were recorded continuously during intubation. The subjects were candidates for coronary bypass grafts, but had good ventricular function (mean ejection fraction $0.68 \pm 0.13 \mathrm{SD}$ ).

From their reduced levels after induction, $B P$, cardiac index and systemic vascular resistance increased to awake levels following intubation. Mean CSBF in nonbetablocked patients increased to awake level along with $B P$. More myocardial oxygen was extracted and consumed after intubation, but lactate extraction continued: these data are evidence of adequate axygen supply. Induction with either halothane or morphine effectively prevented the hypertensive response to intubation. Acute beta blockade led to less increase in heart rate from intubation.

\section{Key words}

HEART: coronary artery disease, myocardial function, anaesthetics; ANAESTHETICS, VOLATILE: halothane; ANALGESICS: morphine; INTUBATION ENDOTRACHEAL: complications.

From the Department of Anaesthesia, Dalhousie University, Halifax, Nova Scotia and the Departments of Anesthesiology and Cardiovascular Surgery, CedarsSinai Medical Center, Los Angeles, California.

Address correspondence to: Dr. E.A. Moffitt, Sir

Charles Tupper Medical Building, University Avenue, Halifax, Nova Scotia, B3H $4 \mathrm{H} 7$.
The circulatory responses to laryngoscopy and endotracheal intubation were first documented by King et al. ${ }^{1}$ in 1951. They found that laryngoscopy increased blood pressure and heart rate, with deep anaesthesia abolishing the response. They noted that these changes were initiated by laryngoscopy before intubation. Since then other studies have examined these phenomena and explored ways of obtunding them. ${ }^{2-9}$ The risk of a major response, particularly in patients with coronary disease or hypertension, is of myocardial oxygen supply being exceeded by greatly increased consumption, causing ischaemia. The haemodynamic changes associated with intubation have been well studied, but effects on myocardial oxygenation and coronary flow have not been published. We now present these haemodynamic responses of laryngoscopy and intubation, correlated with measurements of myocardial oxygenation in coronary patients, after induction with either halothane or morphine and oxygen. In 29 patients coronary blood flow was measured and myocardial oxygen and lactate metabolism quantitated.

\section{Methods}

This study included 29 patients of whom 17 were included in our previous study ${ }^{10}$ of halothane and morphine anaesthesia. The protocol had approval of the Human Subjects Committee and informed signed consent was granted. The subjects were typical candidates for coronary artery bypass grafting (CABG). The 23 males and six females had a mean age of $58 \pm 8$ years; mean surface area was $1.90 \mathrm{~m}^{2}$. The patients selected were those with ventricular function preserved and no other complicating conditions. At catheterization their mean LVEDP was $14 \pm 5 \mathrm{mmHg}$ (SD) and mean ejection fraction was $0.68 \pm 0.13$. Disability by NYHA Class was II -11 , III -12 and IV -6 patients. 
Twenty-one patients had a previous myocardial infarction. Eighteen of the 29 patients were taking propranolol but were concluded not to have complete beta adrenergic blockade, based on the propranolol doses and preoperative heart rates.

After premedication with secobarbitone (mean $210 \pm 36 \mathrm{mg}$ ) and using local anaesthesia, a radial arterial needle was inserted, plus two thermodilution catheters via the right internal jugular vein. One was placed in the pulmonary artery ${ }^{11}$ and the other $^{12}$ in the midcoronary sinus, aided by fluoroscopy. The latter measured total coronary sinus blood flow (CSBF), and permitted sampling of coronary venous blood. The Ganz catheter ${ }^{12}$ measures by thermodilution, all coronary sinus flow and allows sampling of coronary venous blood. Coronary sinus blood is almost exclusively that from left ventricular muscle,,$^{13}$ that is, the venous effluent from the left coronary artery. To measure CSBF, fluid at room temperature is infused by pump and emerges near the catheter tip. Two temperatures are measured: by an internal thermistor within the catheter lumen and an external thermistor downstream from the infusing port. Temperature changes in the latter, caused by the infusate cooler than CS blood, are proportional to the rate of CS blood flow. This method gives results closely comparable to the argon-washin method. ${ }^{14}$ The catheter must be placed in midcoronary sinus by fluoroscopy; elevated right atrial pressure will affect the measurement.

Each sequential study consisted of measuring CSBF, duplicate cardiac outputs, intracardiac and arterial pressures, plus arterial and CS samples for oxygen saturation, haemoglobin and lactate content. ${ }^{10}$ Other variables were calculated. ${ }^{15} \mathrm{MVO}_{2}$ is derived from CSBF multiplied by the arterio-CS difference of oxygen content. Studies were done before induction, before laryngoscopy and approximately one minute after tracheal tube placement. In addition, heart rate, blood pressure and CSBF were continuously recorded during the act of intubation.

In 17 patients induction of anaesthesia began with thiopentone (mean dose $151 \mathrm{mg}$ ). This was followed by halothane with oxygen at inspired halothane concentrations (up to three per cent) sufficient to reduce blood pressure by 30 per cent, for a mean of 11 minutes before the preintubation study. These 17 patients were divided into three groups: (1) six patients (Halothane Group $I$ in
Figures) who had morphine $\left(0.25 \mathrm{mg} \cdot \mathrm{kg}^{-1}\right)$ premedication IV given 45 minutes before induction; (2) five patients (Halothane Group II) given morphine $\left(0.25 \mathrm{mg} \cdot \mathrm{kg}^{-1}\right)$ IM one hour before coming to the OR; (3) six patients premedicated like Group I patients and also given propranolol $\left(0.1 \mathrm{mg} \cdot \mathrm{kg}^{-1}\right)$ 45 minutes before induction. In 12 patients morphine was infused IV $\left(1.0 \mathrm{mg} \cdot \mathrm{kg}^{-1}\right)$, also to reduce arterial pressures by 30 per cent, over a mean duration of 17 minutes. Diazepam (mean dose $12 \mathrm{mg}$ ) was also given before intubation to those patients receiving morphine. Six patients prior to receiving morphine also were given IV propranolol $\left(0.1 \mathrm{mg} \cdot \mathrm{kg}^{-1}\right) 45$ minutes before induction. Nine of the 12 patients given propranolol were not taking this drug preoperatively. Lead V 5 of the electrocardiogram was recorded. All 29 patients received pancuronium $\left(0.1 \mathrm{mg} \cdot \mathrm{kg}^{-1}\right)$, but no intravenous fluid other than as vehicle for drugs.

Statistical analyses by paired $\mathrm{t}$-tests were done using data for all 29 patients, comparing observations before laryngoscopy to those one minute postintubation. By unpaired t-tests, variables for the 12 patients who received IV propranolol were compared with those for the 17 not thus pretreated, at the prelaryngoscopy and postintubation times.

\section{Results}

The Table presents a comparison of variables at the peak pressure response, approximately one minute after tracheal tube placement, to the prelaryngoscopy state. The changes in all variables were very highly significant $(p<0.001)$; except for lactate extraction and pulmonary capillary wedge pressure. Mean values for mean arterial pressure, cardiac index, heart rate and systemic vascular resistance all increased, as did those for CSBF and $\mathrm{MVO}_{2}$. Oxygen content of CS blood decreased. No individual myocardium produced lactate during induction or intubation; no changes in ST segment configuration were seen.

Figure 1 depicts the continuous recording of arterial pressure, ECG and the two temperature thermistors of the CS catheter. This patient, who had a halothane induction, had not been taking a beta-blocking drug and did not receive IV propranolol. The internal (INT) thermistor trace is the infusate temperature within the catheter. The external (EXT) probe records temperature of coronary sinus blood downstream from the catheter tip, as 


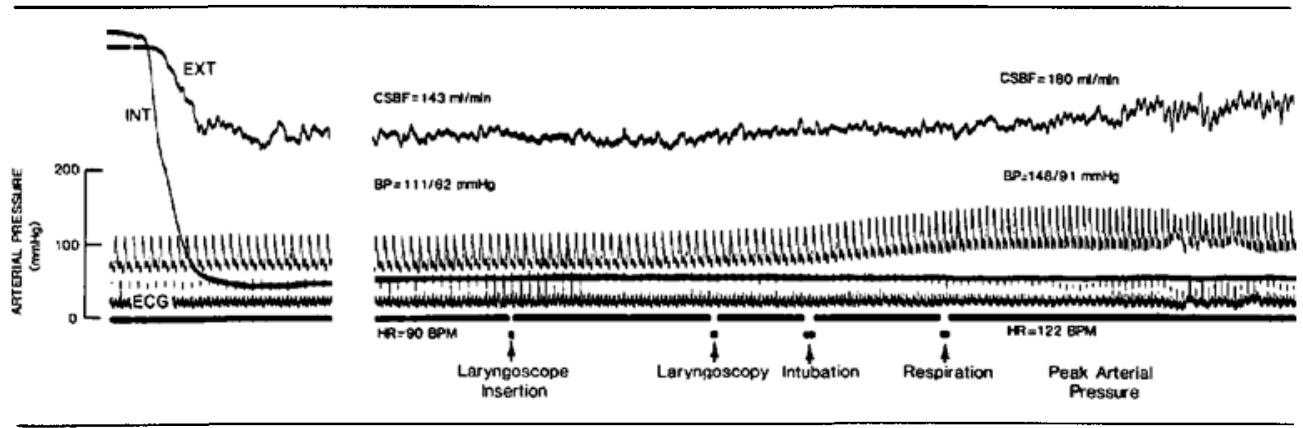

FIGURE I Continuous recording of arterial pressure, heart rate and CSBF during intubation in one patient. The EXT thermistor indicates temperature of CS blood downstream from infusing port. Events during intubation are marked. See text.

TABLE Combined results $(n=29)$

\begin{tabular}{|c|c|c|}
\hline & $\begin{array}{l}\text { Before } \\
\text { laryngoscopy }\end{array}$ & $\begin{array}{l}\text { Peak pressure } \\
\text { response }\end{array}$ \\
\hline \multicolumn{3}{|l|}{ MAP } \\
\hline $\begin{array}{l}\mathrm{mmHg} \\
\mathrm{CI}\end{array}$ & $63 \pm 10$ & $93 \pm 18^{*}$ \\
\hline$L \cdot \min ^{-1} \cdot m^{-2}$ & $2.36 \pm 60$ & $2.70 \pm .70^{*}$ \\
\hline $\begin{array}{l}\text { Rate } \\
\text { beats/minute }\end{array}$ & $68 \pm 11$ & $81 \pm 16^{*}$ \\
\hline $\begin{array}{l}\text { SVR } \\
\text { dynes } \cdot \mathrm{sec} \cdot \mathrm{cm}^{-5}\end{array}$ & $1039 \pm 288$ & $1388 \pm 398^{*}$ \\
\hline CSBF & & \\
\hline $\begin{array}{l}\mathrm{ml} \cdot \mathrm{min}^{-1} \\
\mathrm{CSO}_{2}\end{array}$ & $84 \pm 42$ & $103 \pm 50^{*}$ \\
\hline $\mathrm{ml} \cdot \mathrm{dl}^{-1}$ & $8.9 \pm 1.8$ & $7.6 \pm 1.3^{*}$ \\
\hline $\begin{array}{l}\mathrm{MVO}_{2} \\
\mathrm{ml} \cdot \mathrm{min}^{-1}\end{array}$ & $5.8 \pm 3.3$ & $8.4 \pm 4.2^{*}$ \\
\hline Lactate & & \\
\hline $\begin{array}{l}\text { extraction } \% \\
\text { PC wedge pressure }\end{array}$ & $35 \pm 15$ & $31 \pm 14$ \\
\hline $\mathrm{mmHg}$ & $12 \pm 3$ & $14 \pm 6$ \\
\hline
\end{tabular}

Mean \pm SD

${ }^{*} \mathrm{p}<0.001$.

influenced by the cooler injectate and CS flow rate. Stages in the act of laryngoscopy and tracheal tube placement are identified. Blood pressure rose from $111 / 62$ to $148 / 91 \mathrm{mmHg}$, with CSBF also increasing from 143 to $180 \mathrm{ml} \cdot \mathrm{min}^{-1}$. Heart rate increased from 90 to 122 beats/minute. The pressure began to rise from laryngoscopy by the time of the intubation marker.

Figures 2 through 4 illustrate the responses of MAP, heart rate and CSBF in the five groups of patients, measured from their continuous recordings. For comparison, their state before induction is included with the four measurements related to intubation. The two halothane groups and the morphine group are those we previously reported, ${ }^{10}$ with the addition now of groups of propranolol pretreated patients. All intubations were performed in less than one minute.

Figure 2: Compared to prelaryngoscopy, MAP increased in all groups, including those pretreated with propranolol. Note the pressure rise from laryngoscopy in patients not given IV propranolol. The mean MAP of 93 after intubation was a return to the awake pressure (mean $89 \mathrm{mmHg}$ ).

Figure 3: Coronary sinus blood flow increased after intubation in two groups who were not acutely betablocked and in the propranolol-halothane group. The mean of 103 also was a return to that when awake (mean $100 \mathrm{ml} / \mathrm{min}^{-1}$ ).

Figure 4: Mean heart rate was slow in the awake state, did not change significantly on induction, but increased after intubation in three groups. Mean heart rate in the two groups given propranolol was significantly lower $(\mathrm{p}<0.05)$ than for the patients not acutely betablocked, both after induction and after intubation. This was the only statistically significant difference between these 12 and the other 17 patients.

\section{Discussion}

King et al. ${ }^{1}$ published the classic paper in 1951 on haemodynamic changes from intubation. This must have been one of the earliest studies of continuous direct measurement of blood pressure and electrocardiogram. They gave, both to man and dogs, various combinations of agents in use at that time, including muscle relaxants. The rapid rise in pressure from laryngoscopy alone was graphically 


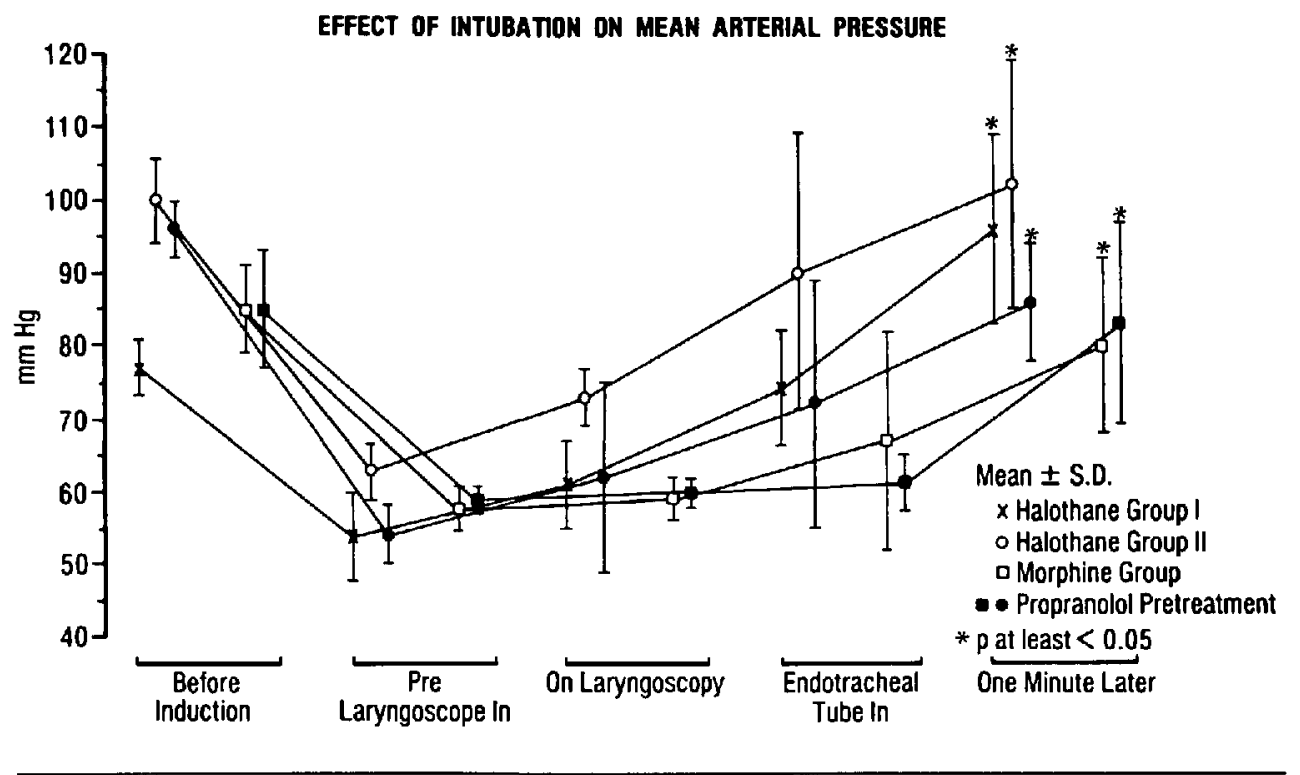

FIGURE 2 Halothane Group I (six patients) had morphine premedication IV in the operating room. Halothane Group II (five patients) had morphine IM before coming to the OR. Six patients each, receiving halothane or morphine induction, were given acute beta blockade. The statistical analysis compared results at one minute postintubation to prelaryngoscopy. MAP increased to awake values on intubation in all groups.

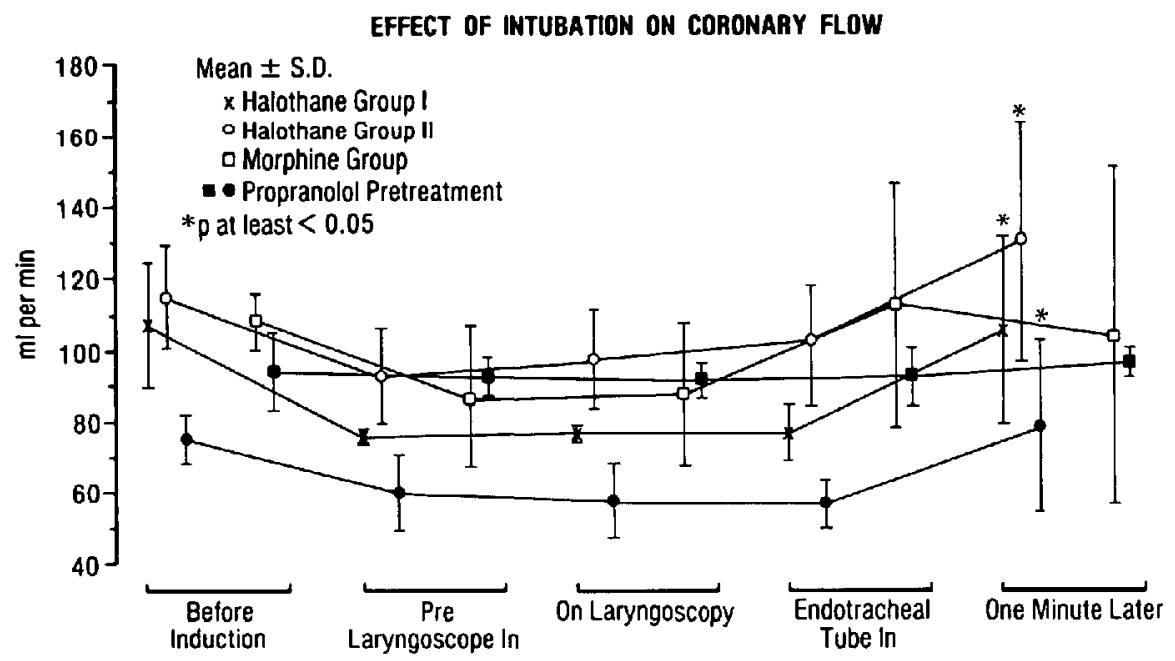

FIGURE 3 Coronary flow increased after intubation in two groups not acutely betablocked, and in the propranolol-halothane group. 


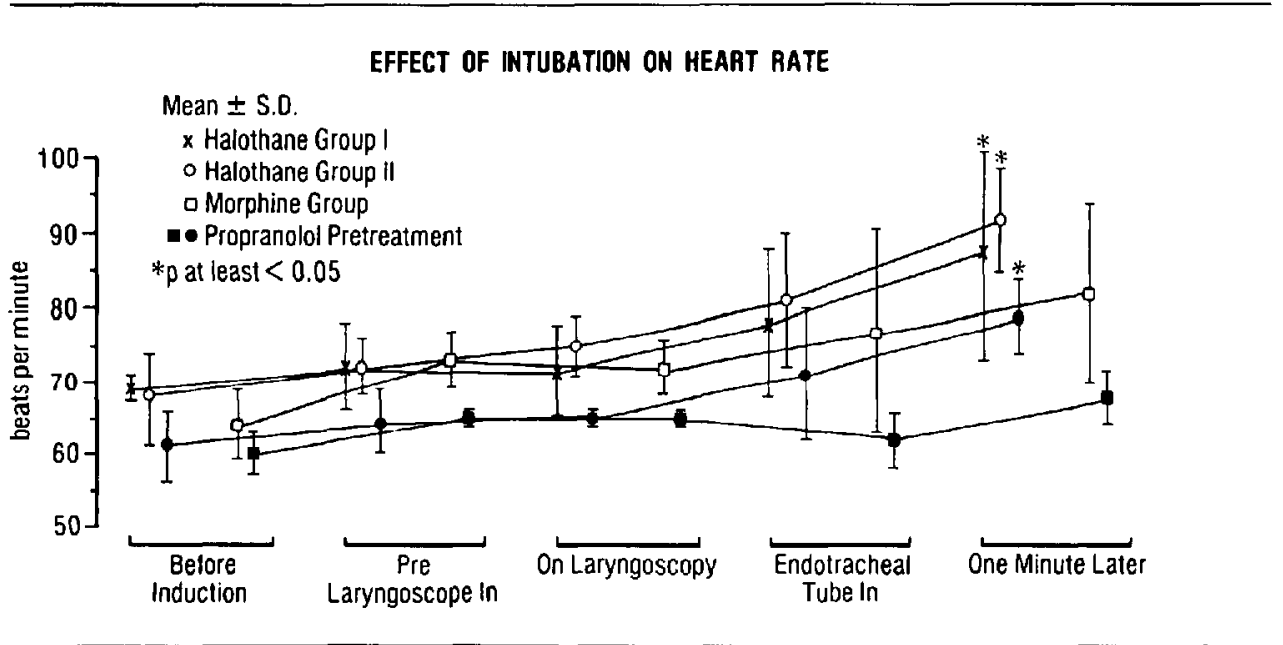

FIGURE 4 In the 12 patients, after acute betablockade, rate was slower than in the other 17 patients, after intubation.

illustrated. They showed that during light anaesthesia, effects were marked; deep anaesthesia abolished the response. They postulated that decreased parasympathetic, or increased sympathetico-adrenal, activity caused the pressure rise and cardioaccelerator action, the heart rate increase. The same group in $1960^{3}$ concluded that the pressure change was from sympathetic stimulation and not vagal in origin. Later workers have looked at the ability of various drugs to obtund these reflexes: lidocaine, ${ }^{5,8}$ muscle relaxants, ${ }^{6}$ adrenergic blocking drugs ${ }^{4}$ and vasodilating drugs. ${ }^{7,9}$

The presence of these autonomic reflexes is commonly known, plus the importance of preventing them, particularly in patients with coronary artery disease or hypertension. There have been no reports of the effects of increased blood pressure and heart rate on coronary flow and myocardial oxygenation. Use of the CS catheter in another study ${ }^{10}$ gave us the opportunity to examine closely these relationships.

Patients having $\mathrm{CABG}$ have three events from which myocardial ischaemic episodes are more likely to occur. Endotracheal intubation, sternal sawing and aortic root dissection will all cause hypertension and tachycardia unless autonomic stimulation is prevented. Of these, only intubation after a quiet, controlled induction, can be studied without other complicating effects from the surgical intervention. In this study we focused on the second-by-second responses to laryngoscopy and intubation. The primary criterion of depth of anaesthesia and readiness for intubation was a $30-35$ per cent decrease in blood pressure, after ten minutes of halothane or $1 \mathrm{mg} \cdot \mathrm{kg}^{-1}$ of IV morphine over 17 minutes. We examined the effects of acute betablockade from $7-8 \mathrm{mg}$ of propranolol given 45 minutes earlier.

We previously presented the study of 18 of these patients ${ }^{10}$ from the awake state through to initiation of heart-lung bypass. The present report examines more closely the act of intubation in 17 of these patients and compares their responses to those of 12 like patients who, before halothane or morphine induction, had imposed acute beta blockade.

The characteristics of the subjects studied must be noted since others may react differently. They all needed CABG but had preserved ventricular function. There were no other complicating factors: hypertension, LV aneurysm, valvular or pulmonary disease, recent myocardial infarction or congestive heart failure. However, 11 were not taking betaadrenergic drugs; nine of these 11 patients were amongst the 12 given IV propranolol. We concluded the other 17 patients did not have complete beta blockade, based on their preoperative propranolol doses and heart rates. Their partial beta blockade may have been a major reason for the absence of differences between the two groups, except in heart rate. 
The CS thermodilution catheter when placed accurately in the midsinus by fluoroscopy makes possible measurement of total coronary venous flow in about 40 seconds. Duplicate measurements done two minutes apart in 12 awake patients were $113.8 \pm 0.1$ and $112.9 \pm 0.1 \mathrm{ml} \cdot \mathrm{min}^{-1}$. Wide variations in flow are regularly seen between awake patients with coronary artery lesions, a major influence being the arterial pressure at the time. ${ }^{16}$ Sampling for oxygen and lactate from CS blood gives information only on global left ventricular oxygenation. Lactate from localized regions of anaerobic metabolism could be hidden in the large pool of blood from adequately oxygenated areas of muscle. More lactate in CS blood than in arterial indicates global ischaemia.

\section{Haemodynamic responses}

Seconds after insertion of the laryngoscope, arterial pressure, heart rate, cardiac index and systemic resistance began to increase. These autonomic reflexes were apparently partially obtunded by the halothane or morphine, since haemodynamic indices returned only to those of the awake state. While coronary flow appears to be directly related to arterial pressure in awake patients, CSBF did not fall as much on induction as did blood pressure. The safety factor was the major reduction of blood pressure during induction, which reduced cardiac work and increased CS oxygen content, thus decreasing $\mathrm{MVO}_{2}$. Blood pressure increased also in the patients given acute beta blockade although their rate change was less. Unfortunately, we did not measure halothane concentration, but anaesthetic depth was adjusted to maintain a steady 30-35 per cent decrease in blood pressure for ten minutes, without requirement for drug or fluid therapy. The increase in pressure on intubation was due to elevation of rate, cardiac index and systemic vascular resistance.

\section{Myocardial metabolic effects}

With the rise in blood pressure, CSBF, which equates with left coronary inflow, went up 28 per cent. Coronary dilatation possibly also occurred as a result of greater oxygen consumption. Without a change in arterial oxygen content, CS content decreased 15 per cent, which with the greater CSBF, led to a calculated 45 per cent increase in $\mathrm{MVO}_{2}$. Higher cardiac output and work caused more oxygen to be consumed. We saw no evidence that global oxygen supply was exceeded, since lactate extraction continued in every myocardium; mean extraction remained normal. No conclusions are possible on the adequacy of regional oxygenation, but no ST changes occurred. These hearts handled the increased work after intubation, starting from the reduced work and oxygen need present after induction. Decreased blood pressure, cardiac index and a slow rate was an appropriate base from which to begin intubation. Acute beta blockade before induction was effective in minimizing the rate response to intubation and was not detrimental to contractility. ${ }^{17}$ Means of preventing the autonomic response to intubation by the use of other drugs, were not explored.

In summary, after a halothane or morphine induction, the haemodynamic changes from laryngoscopy and intubation were increases, back to awake levels of blood pressure, cardiac index and systemic resistance. While we could not justify studying the response to intubation, after induction with a lighter anaesthetic depth, the major increase in blood pressure, regularly seen then, is well known. Compared to the reproduceable hypertension on intubation with light anaesthesia, the observed return to awake pressure levels indicates effective blunting of the autonomic response, while not abolishing it completely.

Patients given $0.1 \mathrm{mg} \cdot \mathrm{kg}^{-1}$ of propranolol IV, 45 minutes before induction, had lower heart rates after induction and after intubation than those receiving preoperative propranolol and not acutely given a large dose intravenously. Hence this pretreatment blunted the heart rate response to intubation but not the blood pressure response. Coronary blood flow and myocardial oxygen consumption increased but global aerobic oxygenation of the left ventricle continued.

\section{References}

1 King $B D$, Harris $L C J r$, Greifenstein FE, Elder $J D$ $J r$, Dripps $R D$. Reflex circulatory responses to direct laryngoscopy and tracheal intubation performed during general anesthesia. Anesthesiology 1951; 12: 556-66.

2 Wycoff CC. Endotracheal intubation: effects in blood pressure and pulse rate. Anesthesiology 1960; $21: 153-8$.

3 DeVault $M$, Greifenstein FE, Harris LC Jr. Circu- 
latory responses to endotracheal intubation in light general anesthesia - the effect of atropine and phentolamine. Anesthesiology 1960; 21:360-2.

4 Prys-Roberts C, Föex $P$, Biro GP, et al. Studies of anesthesia in relation to hypertension. $V$ : Adrenergic beta-receptor blockade. $\mathrm{Br} J$ Anaesth 1973; 45: 671-80.

5 Denlinger JD, Ellison $N$, Ominsky AJ. Effects of intratracheal lidocaine on circulatory responses to tracheal intubation. Anesthesiology 1974; 41 : 409-12.

6 Stoelting RK, Peterson C. Circulatory changes during anesthetic induction: impact of d-tubocurarine pretreatment, thioamylal, succinylcholine, laryngoscopy and tracheal lidocaine. Anesth Analg. 1976; 55: 77-81.

7 Carroll RM, Laravuse RB, Schauble JF. Left ventricular function during aortic surgery. Arch Surg 1976; 111: 740-3.

8 Stoelting $R K$. Circulatory changes during direct laryngoscopy and tracheal intubation: influence of duration of laryngoscopy with or without prior lidocaine. Anesthesiology 1977; 47: 381-4.

9 Stoelting RK. Attenuation of blood pressure response to laryngoscopy and tracheal intubation with sodium nitroprusside. Anesth Analg 1979; 58: 116-9.

10 Moffit EA, Sethna DH, Bussell JA, Raymond MJ, Matloff $J M$, Gray RJ. Myocardial metabolism and hemodynamic responses to halothane or morphine anesthesia for coronary artery surgery. Anesth Analg 1982; 61: 979-85.

11 Swan HJ, Ganz W, Forrester JS, et al. Catheterization of the heart in man with use of a flowdirected, balloon-tipped catheter. N Engl J Med 1970; 283: 447-50.

12 Ganz W, Tamura K, Marcus HS, Donoso R, Yoshida $S$, Swan HJC. Measurement of coronary sinus blood flow by continuous thermodilution in man. Circulation 1971; 44: 181-95.

13 James $T N$. Anatomy of the heart, normal and pathologic, as related to cardiac function. In: Gordon BL, Ed. Clinical cardiopulmonary physiology. New York: Grune and Stratton, 1960: 8-32.

14 Sonntag $H$, Merin RG, Donath U, Radke J. Schenk $H-D$. Myocardial metabolism and oxygenation in man, awake and during halothane anesthesia. Anesthesiology 1979; 51: 204-10.

15 Yang SS, Bentivoglio LG, Maranhao V, et al. From cardiac catheterization data to hemodynamic vari- ables. Philadelphia: F.A. Davis Company, 1972, 37-43.

16 Moffitt EA, Scovil JE, Barker RA, et al. Myocardial metabolism and haemodynamic responses in high-dose fentanyl anaesthesia for coronary patients. Can Anaesth Soc J 1984; 31: 611-8.

17 Moffit E. Sethna D, Bussell J, Raymond M, Matloff $J$, Gray $R$. Hemodynamics and myocardial metabolism after acute $\beta$-adrenergic blockade in coronary patients. Anesth Analg 1984; 63: 540-1.

\section{Résumé}

Les effets de l'intubation endotrachéale sur l' hémodyna. mique et l'oxygénation myocardique ont été examinés chez 17 patients après induction d̀ l' halothane et chez 12 patients après administration intraveineuse de $1 \mathrm{mg} \cdot \mathrm{kg}^{-1}$ de morphine. Six patients ayant reçu l'un ou l'autre des agents anesthésiques ont été pré-traités avec du propranolol $\mathrm{IV}\left(0.1 \mathrm{mg} \cdot \mathrm{kg}^{-1}\right) 45$ minutes au préalable. La pression artérielle ainsi que les pressions intracardiaques, le débit cardiaque ainsi que le flot sanguin total du sinus coronaire (CSBF) tous les deux par thermodilution, ont été dêterminés. Il en est de même pour les différences d'oxygène entre le contenu artériel et le contenu du sinus coronaire. L'hêmoglobine ainsi que le lactate ont été mesurés. La pression artérielle (BP). la fréquence cardiaque et le CSBF ont été enregistrés continuellement lors de l'intubation. Les sujets étaient des candidats a des pontages aorto-coronariens mais avaient une bonne fonction ventriculaire (fraction d'éjection moyenne $0.68 \pm 0.13 \mathrm{SD}$ ).

Après leurs valeurs réduites post-induction, la tension artérielle, l'index cardiaque et la résistance vasculaire systémique ont augmenté à des valeurs identiques à celles de l'état de réveil post-intubation. Le CSBF moyen chez les patients non bêta-bloqués a augmenté à des niveaux identigues aux valeurs à l'état de réveil. Il en est de même pour la tension artérielle. Plus d' oxygène myocardique a ésé extrait et consommé après l' intubation, mais l'extraction de lactate a continué, indiquant que l'apport d'oxygène êtait adéquat. L'induction avec les deux agents a empêché efficacement la réponse hypertensive à l'intubation. Le blocage bêta aigu des patients a amené moins d'augmentation de la fréquence cardiaque lors de l'intubation. 